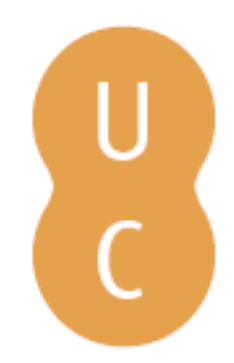

\title{
pompalina
}

\section{Alguns comentários de Amato: entre a estranheza e a realidade}

Autor(es): $\quad$ Torrão, João Manuel Nunes

Publicado por: UA Editora - Universidade de Aveiro; Imprensa da Universidade de

URL

persistente: URI:http://hdl.handle.net/10316.2/35703

DOI: $\quad$ DOI:http://dx.doi.org/10.14195/978-989-26-0941-6_17

Accessed : $\quad$ 26-Apr-2023 14:06:47

A navegação consulta e descarregamento dos títulos inseridos nas Bibliotecas Digitais UC Digitalis, UC Pombalina e UC Impactum, pressupõem a aceitação plena e sem reservas dos Termos e Condições de Uso destas Bibliotecas Digitais, disponíveis em https://digitalis.uc.pt/pt-pt/termos.

Conforme exposto nos referidos Termos e Condições de Uso, o descarregamento de títulos de acesso restrito requer uma licença válida de autorização devendo o utilizador aceder ao(s) documento(s) a partir de um endereço de IP da instituição detentora da supramencionada licença.

Ao utilizador é apenas permitido o descarregamento para uso pessoal, pelo que o emprego do(s) título(s) descarregado(s) para outro fim, designadamente comercial, carece de autorização do respetivo autor ou editor da obra.

Na medida em que todas as obras da UC Digitalis se encontram protegidas pelo Código do Direito de Autor e Direitos Conexos e demais legislação aplicável, toda a cópia, parcial ou total, deste documento, nos casos em que é legalmente admitida, deverá conter ou fazer-se acompanhar por este aviso.

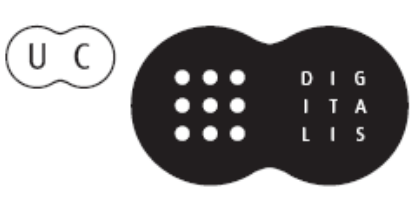




\section{HUMANISMO E CIÊNCIA Antiguidade e Renascimento}

António Manuel Lopes Andrade

Carlos de Miguel Mora

João Manuel Nunes Torrão
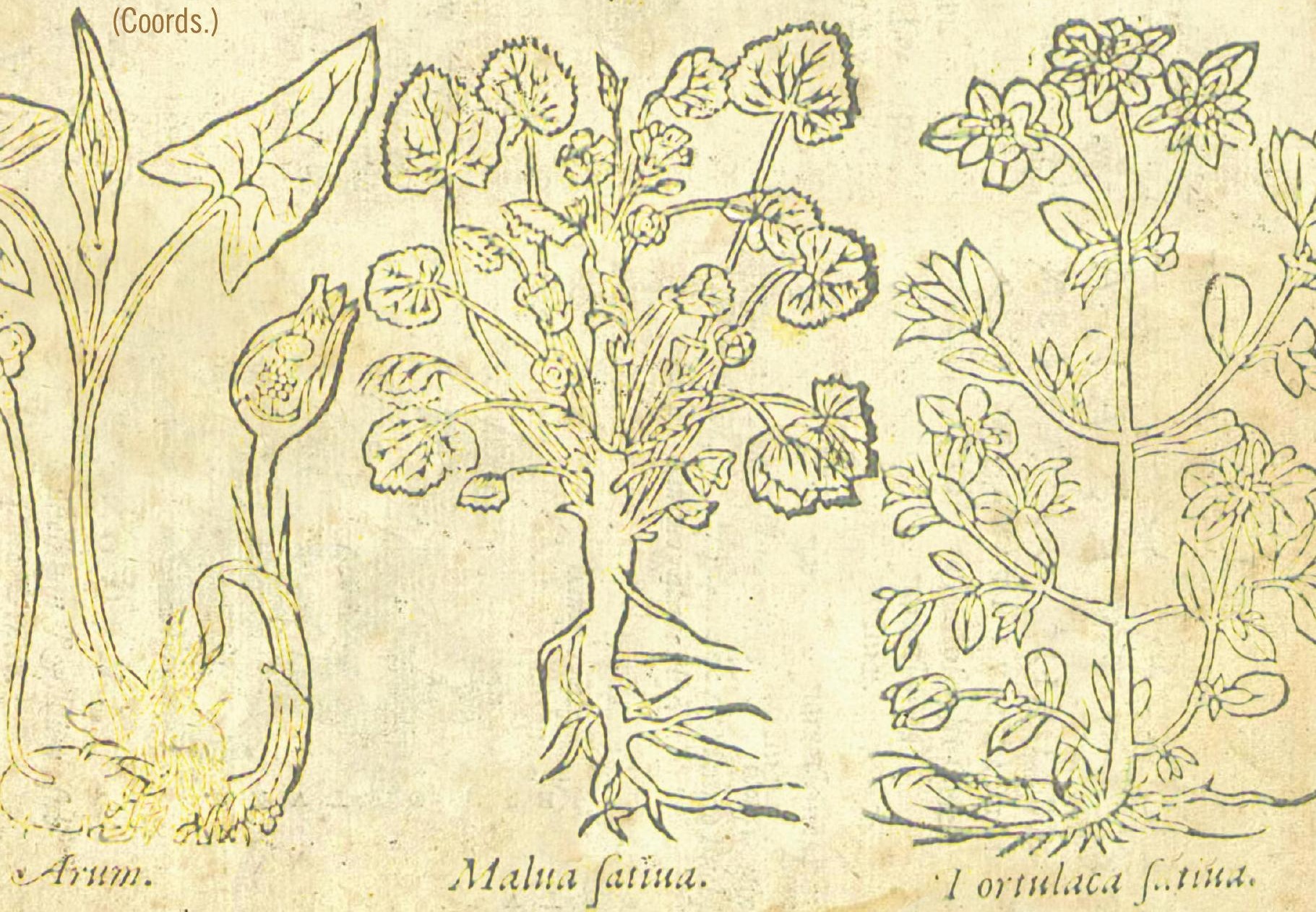

Aveiro I Coimbra I São Paulo 2015

UA Editora - Universidade de Aveiro I Imprensa da Universidade de Coimbra I Annablume 
Este volume resulta de várias iniciativas desenvolvidas no âmbito do projecto de I\&D "Dioscórides e o Humanismo Português: os Comentários de Amato Lusitano" (http://amatolusitano.web.ua.pt), recoIhendo contribuições de mais de duas dezenas de colaboradores, tanto de membros da equipa como de outros investigadores nacionais e estrangeiros. Entre os eventos que estiveram na origem deste livro destacam-se as três edições do Ciclo de Conferências promovido pelo projecto, realizadas entre 2010 e 2013, e sobretudo o Colóquio Internacional "Dioscórides e o Humanismo Português: os Comentários de Amato Lusitano", que decorreu no Departamento de Línguas e Culturas da Universidade de Aveiro, nos dias 21 e 22 de Novembro de 2013.

0 objectivo principal do projecto é a edição e tradução para português dos dois livros que Amato Lusitano dedicou ao comentário do tratado grego De materia medica de Dioscórides, ou seja, o Index Dioscoridis (Antuérpia, 1536) e as In Dioscoridlis Anazarbei de medica materia libros quinque... enarrationes (Veneza, 1553), estando contemplada, também, a tradução de mais duas obras directamente correlacionadas com os livros do médico português: a montante, a do próprio tratado grego de Dioscórides; a jusante, a do livro intitulado Apologia adversus Amathum Lusitanum (Veneza, 1558) de Pietro Andrea Mattioli.

OBRA PUBLICADA COM A COORDENAÇÃO

CIENTÍFICA DE:

Centro de Línguas, Literaturas e Culturas da Universidade de Aveiro

Centro de Estudos Clássicos e Humanísticos da Universidade de Coimbra

Cátedra de Estudos Sefarditas "Alberto

Benveniste" da Faculdade de Letras da Universidade de Lisboa 


\section{HUMANISMO E CIÊNCIA}

\section{Antiguidade e Renascimento}

ANTÓNIO MANUEL LOPES ANDRADE

CARLOS DE MIGUEL MORA

JOÃO MANUEL NUNES TORRÃO

(COORDS.)

AVEIRO • COIMBRA • SÃO PAULO

2015

UA EDITORA • UNIVERSIDADE DE AVEIRO

IMPRENSA DA UNIVERSIDADE DE COIMBRA

ANNABLUME 


\section{HUMANISMO E CIÊNCIA: Antiguidade e Renascimento}

\author{
EDIÇÃO

UA EDITORA • UNIVERSIDADE DE AVEIRO
IMPRENSA DA UNIVERSIDADE DE COIMBRA
ANNABLUME

ORGANIZAÇÃO E COORDENAÇÃO EDITORIAL ANTÓNIO MANUEL LOPES ANDRADE

CARLOS DE MIGUEL MORA

JOÃO MANUEL NUNES TORRÃO

\author{
DESIGN DA CAPA \\ MEIOKILO DESIGN STUDIO
}

DESIGN

CARLOS COSTA

IMPRESSÃO E ACABAMENTO

SERSILITO • MAIA

ISBN

UA • 978-972-789-434-5

IUC • 978-989-26-0940-9

\section{ISBN DIGITAL}

UA • 978-972-789-435-2

IUC • 978-989-26-0941-6

DOI

http://dx.doi.org/10.14195/ 978-989-26-0941-6

DEPÓSITO LEGAL 368241/13

TIRAGEM 500 Exemplares

(C) 2015

UA EDITORA • UNIVERSIDADE DE AVEIRO IMPRENSA DA UNIVERSIDADE DE COIMBRA

ANNABLUME

\section{COMISSÃO CIENTÍFICA}

António Manuel Lopes Andrade

Carlos de Miguel Mora

Delfim Ferreira Leão

Henrique Leitão

João Manuel Nunes Torrão

Maria de Fátima Reis

Maria do Céu Zambujo Fialho

Miguel Ángel González Manjarrés

\section{TEXTOS}

Adelino Cardoso

Ana Leonor Pereira

Ana Margarida Borges

António Guimarães Pinto

António Maria Martins Melo

Bernardo Mota

Carlos A. Martins de Jesus

Carlos de Miguel Mora

Cristina Santos Pinheiro

Donald Beecher

Emília Oliveira

Isabel Malaquias

James W. Nelson Novoa

Joana Mestre Costa

João Manuel Nunes Torrão

João Rui Pita

Jorge Paiva

José Sílvio Moreira Fernandes

Maria de Fátima Silva

Miguel Ángel González Manjarrés

Rui Manuel Loureiro

Telmo Corujo dos Reis

Teresa Nobre de Carvalho

Vinicije B. Lupis

Virgínia Soares Pereira 


\section{HUMANISMO E CIÊNCIA}

\section{Antiguidade e Renascimento}

ANTÓNIO MANUEL LOPES ANDRADE

CARLOS DE MIGUEL MORA

JOÃO MANUEL NUNES TORRÃO

(COORDS.)

AVEIRO • COIMBRA • SÃO PAULO

2015

UA EDITORA • UNIVERSIDADE DE AVEIRO

IMPRENSA DA UNIVERSIDADE DE COIMBRA

ANNABLUME 
OBRA PUBLICADA

COM A COORDENAÇÃO

CIENTÍFICA DE:

CENTRO DE LÍNGUAS,

LITERATURAS E CULTURAS DA

UNIVERSIDADE DE AVEIRO

CENTRO DE ESTUDOS

CLÁSSICOS E HUMANÍSTICOS DA

UNIVERSIDADE DE COIMBRA

CÁTEDRA DE ESTUDOS SEFARDITAS

"ALBERTO BENVENISTE"

DA FACULDADE DE LETRAS DA

UNIVERSIDADE DE LISBOA 


\section{SUMÁRIO}

PREFÁCIO

1.1 "Teofrasto, Tratado das plantas. No alvor de uma nova ciência" 13

Maria de Fátima Silva

1.2 "Francisco de Melo e os fragmentos de teoria óptica de Pierre Brissot" 21 Bernardo Mota

1.3 "Algumas reflexões sobre as pedras preciosas nos Colóquios dos simples de Garcia de Orta" 37 Rui Manuel Loureiro

1.4 "Estratégias, patronos e favores em Colóquios dos Simples de Garcia de Orta" 63 Teresa Nobre de Carvalho

1.5 "As plantas na obra poética de Camões (épica e lírica)" 95 Jorge Paiva

1.6 "Nicolás Monardes, John Frampton and the Medical Wonders of the New World" .141 Donald Beecher

1.7 "Literatura e Medicina: alguns textos de Justo Lípsio e de dois doutores Luís Nunes" 161 António Guimarães Pinto

1.8 "Ontologias e idiossincrasias dos Amantes, à luz da Archipathologia de Filipe Montalto" ...... 211 Joana Mestre Costa \& Adelino Cardoso

1.9 "Gabriel da Fonseca. A New Christian doctor in Bernini's Rome". .227 James W. Nelson Novoa 


\section{2) DIOSCÓRIDES E O HUMANISMO PORTUGUÊS: OS COMENTÁRIOS DE AMATO LUSITANO}

2.1 "Léxico científico português nos Comentários de Amato: antecedentes e receção"

Ana Margarida Borges

2.2 "Usos medicinais das plantas, em Amato Lusitano: o bálsamo"

António Maria Martins Melo

2.3 "Amato Lusitano e a importância da ilustração botânica no século xVI.

Em torno das edições lionesas das Enarrationes (1558)"

Carlos A. Martins de Jesus

2.4 "Sobre la identificación entre ébano y guayaco en una entrada

del Index Dioscoridis de Amato Lusitano".

Carlos de Miguel Mora

2.5 "Os partos distócicos em Amato Lusitano e em Rodrigo de Castro:

fontes, doutrinas e terapias greco-romanas"

\section{Cristina Santos Pinheiro}

2.6 "Do carvalho ao castanheiro: usos e propriedades medicinais

de fagáceas nas Enarrationes de Amato Lusitano".

Emília Oliveira

2.7 "O mundo mineral nos Comentários a Dioscórides de Amato Lusitano".

Isabel Malaquias \& Virgínia Soares Pereira

2.8 "Alguns comentários de Amato: entre a estranheza e a realidade"

João Manuel Nunes Torrão

2.9 "Caracterização e usos terapêuticos de produtos de origem marinha

nos Comentários de Amato Lusitano a Dioscórides"

José Sílvio Moreira Fernandes

2.10 "La mandrágora de Amato Lusitano: edición, traducción y anotación"

Miguel Ángel González Manjarrés

2.11 "O vinho e os vinhos - usos e virtudes de um dom dos deuses

nas Enarrationes de Amato Lusitano"

Telmo Corujo dos Reis

2.12 "Amatus Lusitanus e Didaco Pirro: due ebrei portoghesi

e cerchia umanistica di Dubrovnik" 481

Vinicije B. Lupis

2.13 "Estudos contemporâneos sobre Amato Lusitano". 513

João Rui Pita \& Ana Leonor Pereira 


\title{
Alguns comentários de Amato: entre a estranheza e a realidade ${ }^{1}$
}

\author{
JOÃO MANUEL NUNES TORRÃO²
}

\section{RESUMO:}

Este texto aborda alguns comentários de Amato Lusitano nas Enarrationes que poderão apresentar algum grau de estranheza para os leitores atuais, ainda que, em alguns casos, seja possível encontrar aproximações e coincidências com situações da atualidade.

\section{PALAVRAS CHAVE:}

Amato Lusitano; Enarrationes; stercus; cicuta; nerion; fungi; aster Atticus.

\section{ABSTRACT:}

This paper discusses some comments by Amatus Lusitanus in Enarrationes, which may appear somewhat strange to modern readers, although in some cases one may possibly find similarities and coincidences with present day situations.

\section{KEYWORDS:}

Amatus Lusitanus; Enarrationes; stercus; cicuta; nerion; fungi; aster Atticus.

1 Este trabalho foi desenvolvido no âmbito do projeto de IED "Dioscórides e o Humanismo Português: os Comentários de Amato Lusitano" (http://amatolusitano.web.ua.pt) do Centro de Línguas, Literaturas e Culturas da Universidade de Aveiro, financiado por Fundos FEDER através do Programa Operacional Factores de Competitividade - COMPETE e por Fundos Nacionais através da FCT - Fundação para a Ciência e a Tecnologia, no âmbito do projeto FCOMP-01-0124-FEDER-009102.

2 Centro de Línguas, Literaturas e Culturas da Universidade de Aveiro: jtorrao@ua.pt. 
Numa leitura algo despreocupada das Enarrationes ${ }^{3}$ de Amato Lusitano, deparamo-nos com alguns comentários que, nos dias de hoje, nos causam alguma estranheza, ainda que, se refletirmos um pouco, seja possível encontrar na atualidade alguns elementos de realidade que, de algum modo, vêm comprovar o antigo provérbio 'nihil sub sole novum'.

Vamos apresentar alguns comentários que nos chamaram a atenção por motivos bem diversos, nomeadamente, a eventual estranheza da situação; o espanto com que Amato os apresenta; as cautelas com que o autor apresenta a sua opiniáo; o paralelismo com outros textos renascentistas.

Não se trata, pois, de um conjunto de comentários ligados por um fio condutor de grande pendor lógico, mas antes de situaçóes bem diferenciadas e autónomas que, por um motivo ou outro, nos chamaram a atenção e nos pareceram merecedoras de registo.

\section{DE STERCORE ANIMALIVM - OS EXCREMENTOS DOS ANIMAIS}

No livro segundo, a enarratio $75^{5}$ aborda as utilizaçóes dos excrementos para efeitos medicinais. É um texto com vinte linhas que tem a particularidade de referir por cinco vezes o nome de Galeno que, assim, se torna o referente por excelência deste comentário. Além destas cinco remissóes para Galeno, há uma outra a Avenzoar e ainda a exploração das ideias do próprio Amato.

O nosso autor vai abordar, sucessivamente:

as fezes de cão: que curam a angina e restringem a disenteria — "anginam curat et dysenteriam constringit” — e, além disso, acrescentadas a outros medicamentos, curam as úlceras malignas - "quoque medicamentis maligna ulcera sanantibus adiungitur";

as do homem: que curam os fleimões da garganta e as anginas — "gutturis phlegmonibus et anginis mederi";

as do lobo: que ajudam nas cólicas graves e sobre as quais Amato, que, nos exemplos anteriores, se socorrera apenas de Galeno, vai, neste caso concreto, aduzir a sua própria experiência, já que

3 Utilizaremos a primeira edição, ainda que tenha havido a colação com as edições posteriores: AMATO LUSITANO, IN DIOSCORIDIS / ANAZARBEI DE MEDICA / MATERIA LIBROS QVINQVE / ENARRATIONES ERVDITISSIMAE / DOCTORIS AMATI LVSITANI MEDICI / AC PHILOSOPHI CELEBERRIMI, / quibus non solum Officinarum Seplasia- / riis, sed bonarum etiam literarum stu- / diosis utilitas adfertur, quum pas- / sim simplicia Graece, Latine, I Italice, Hispanice, Germa- / nice, \& Gallice pro-/ponantur. I Cum Priuilegio Illustriss. Senatus Veneti ad decennium. /VENETIIS / MDLIII.

4 Como se sabe, trata-se de uma expressão bíblica: Eclesiastes, 1.10. Cf. Biblia Sacra iuxta Vulgatam Clementinam. Nova Editio logicis partitionibus aliisque subsidiis ornata a Alberto Colunga, O.P. et Laurentio Turrado. Septima editio. Matriti, La Editorial Católica, MCMLXXXV, p. 606.

5 Enarrationes, pp. 214-215. 
ele próprio procedia à recolha das fezes de lobos para a preparação de medicamentos, dando indicaçóes precisas sobre a maneira como se deveria proceder quando alguém matava um lobo:

\begin{abstract}
Verum ego quum lupus interficitur iubeo illius intestina cum stercore servari ac exsiccata et in pulverem redacta in potu contra colicas affectiones dare, non contemnendo profecto iuvamento
\end{abstract}

Na verdade, eu, quando um lobo é morto, ordeno que os seus intestinos sejam conservados com o estrume e, depois de secos e reduzidos a pó, dados em bebida contra as cólicas graves, coisa que não é, na verdade, uma ajuda desprezível;

as de cabra: que se utilizam nas escrófulas e nos tumores cirróticos, mas que só se devem aplicar em corpos duros ou de camponeses, excluindo, por isso, as crianças e as mulheres, e que servem, ainda, para aliviar as dores de ventre, desde que convenientemente aplicadas:

strumis et scirrhosis tumoribus convenit, praesertim in corporibus duris et rusticorum secus autem puerorum ac mulierum. Extrinsecus quoque pulticulae modo ventri impositum ipsius doloribus subvenit;

e convém às escrófulas e aos tumores cirróticos, sobretudo nos corpos duros e dos camponeses, com exceção, porém, das crianças e das mulheres. Colocado de fora do ventre à moda de papa, também alivia as suas dores;

as de boi, em paralelo com as de pomba: que têm a capacidade de secar e são cáusticas e, por isso, Avenzoar as inclui nos antídotos contra a peste. Esta causticidade era tal que Galeno apresenta a história de uma casa na Ásia que foi queimada com os excrementos de pomba ${ }^{6}$

6 Galeno, De temperamentis, 3: "Siquidem in ea Mysia, quae est Asiae pars, domus hac aliquando ratione conflagrauit. Erat proiectum columbinum stercus, cui iam putri et excalfacto, ac vaporem edenti et tangentibus admodum calido, in propinquo fenestra fuerat, ita ut tam contingeret eius ligna, quae large nuper illita resina fuerant. Media igitur aestate, cum sol plurimus incidisset, accendit tum resinam, tum ligna. Hinc autem et fores quaedam aliae, quae prope fuerant et fenestrae nuper etiam resinae illitae facile ignem conceperant atque ad tectum usque summiserant. Vbi autem excepta semel a tecto est flamma, celeriter in totam domum est grassata.". Citámos a partir de Claudii Galeni Pergameni / DE TEMPERAMENTIS LIBRI III. / DE INAEQVALI INTEMPERIE LIBER I. Thoma Linacro Anglo Interprete. / Cum isagoge in eosdem libros et scholijs marginalibus / longe doctissimis, per lacobum Syluium. / PARISIIS, / Ex officina Christiani wecheli, sub scuto Basiliensi, / in vico lacobaeo: \& sub Pegaso, in vico / Bellouacensi. M. D. XLV. 
At bubulum exsiccatoriae est facultatis veluti columbinum causticae et exedentis potentiae quod Abinzoar inter antidota contra pestem adnumerat et de eo Galenus libro tertio de temperamentis historiam de domo in Asia combusta enarrat;

Mas o de boi, tal como o de pomba, tem a capacidade de secar, e é cáustico e tem o poder de roer pelo que Avenzoar o enumera entre os antídotos contra a peste e, a propósito dele, Galeno, no livro terceiro De temperamentis, conta a história de uma casa queimada na Ásia.

as de cegonha: que Galeno afirma nâo terem efeitos na epilepsia "Ciconiarum vero, comitiali morbo mederi, falsum Galenus invenit";

e, finalmente, as dos lagartos: que, comprovadamente, atacam as névoas dos olhos e as afluências sanguíneas "at lacertarum unice oculorum nebulas eorumque concursus sanguineos delere certi sumus".

Nesta última situação, a afirmação fica a pairar com um tudo-nada de ambiguidade, não nos fornecendo elementos suficientes para podermos afirmar com plena certeza que também aqui entra a experiência de Amato. De facto, apesar de a primeira leitura apontar para essa ideia, já que o autor utiliza a expressão 'certi sumus', pode ficar no ar alguma dúvida, nomeadamente por causa da utilizaçáo da primeira pessoa do plural que, neste caso concreto, pode fazer contraste com a primeira pessoa do singular utilizada quando se referiu aos lobos, atenuando deste modo a afirmação. Assim, é possível que esta primeira pessoa do plural possa ser uma utilização genérica de maneira a não incluir obrigatoriamente o nosso autor através de uma experiência direta.

E se, na verdade, esta utilização dos excrementos nos pode causar alguma impressão, convém não esquecer que, mesmo na atualidade, ainda há quem defenda a sua utilização. De facto, para já não falarmos na urina que, em termos populares era (e ainda continua a ser?) usada como desinfetante, por exemplo para cortes feitos por quem andava a trabalhar no campo, e tem quem defenda a sua utilização para a cura do cancro, tanto no Oriente, como no Ocidente ${ }^{8}$, também os excrementos surgem com utilizaçôes curativas, mesmo em termos da medicina convencional ${ }^{9}$.

7 Veja-se este sítio da internet: http://www.curapelanatureza.com.br/2012/01/conhecendo-urinoterapia.html.

8 Cf. http://www.paulopes.com.br/2010/11/padre-continua-defender-que-pocao-base.html.

9 Cf., por exemplo, http://www.ecycle.com.br/component/content/article/38-no-mundo/1764-tratamento-coreano-utiliza-vinho-medicinal-feito-com-fezes-humanas.html e http://cidadaniatransparencia. blogspot.pt/2013/11/remedio-feito-de-fezes-humanas-pode.html. 


\section{DE CICVTA - A CICUTA}

Amato, na enarratio $82^{10}$ do livro quarto, dedica algumas linhas (onze e meia) à cicuta, onde, como é óbvio, não poderia faltar a referência à morte de Sócrates — "cuius succo olim Socrates, summus philosophus iniuste mortuus fuit".

Além de apontar caraterísticas ligeiramente diferentes de acordo com as regióes onde nasce esta planta — é menos venenosa a nascida na Hispânia e na Itália —, também afirma que ela é venenosa para o homem, mas já serve de alimento para o gado e para o estorninho — "homini enim cicuta venenum est, pecudi vero et sturno pabulum".

No entanto, esta enarratio tem uma particularidade: de facto, Amato, através da sua experiência pessoal, chegou à conclusão de que a cicuta deveria ser classificada como quente e não como fria, como todos os autores fazem, mas, estranhamente, não se atreve a assumir frontalmente esta sua posição com o argumento de não querer contradizer toda a Antiguidade:

\footnotetext{
Ego vero quandoque cicutae radicem gustans, eam valenter linguam rodere, ac urere deprehendi, qua de causa illam calidam esse, in dubium trahebam, et nisi procul dubio universae antiquitati contradixissem, illam calidam omnino asseverarem.

Eu, na verdade, ao provar a raiz da cicuta, compreendi que ela rói e queima muito a língua e, por isso, tinha dúvidas se ela era quente e, se não estivesse a contradizer, sem sombra de dúvida, toda a Antiguidade, asseguraria que ela era completamente quente.
}

Pode, realmente, parecer estranha esta posição, nomeadamente atendendo a que, em outras circunstâncias, o autor não hesita em apresentar a sua opinião pessoal de forma clara. Julgamos que, neste caso, terá sido todo o peso histórico da caraterização da cicuta, onde se inclui a morte de Sócrates que, como dissemos, ele próprio refere, que aqui acabou por deixar o nosso autor numa posição algo desconfortável.

\section{DE NERIO - O ELOENDRO}

A enarratio 85 do livro quatro ${ }^{11}$ é dedicada ao eloendro e, para além de mais algumas informaçôes de interesse, importa referir duas das temáticas abordadas.

10 Enarrationes, p. 417.

11 Enarrationes, pp. 418-419. 
A primeira aponta para a identificação desta planta com a que dava as famosas flores que o protagonista do romance de Apuleio ${ }^{12}$, quando estava transformado em burro, pensou que eram rosas:
Nascitur ad ripas fluviorum nerion, perpulchras ferens rosas, quas Apuleius in asinum versus, veras rosas putavit, sed ultimo diversas dignovit.
O eloendro nasce junto das margens dos rios, dando rosas muito bonitas, que Apuleio, transformado em burro, considerou que eram rosas verdadeiras, mas, por fim, verificou que eram diferentes.

A segunda está relacionada com a Península Ibérica e com uma tradição muito antiga e que hoje divide claramente opinióes, as touradas.

De facto, de acordo com as palavras de Amato, as crianças utilizavam os ramos deste arbusto para prepararem dardos que atiravam aos touros. $\mathrm{O}$ texto, sendo bastante sucinto, não nos dá mais informação sobre as circunstâncias em que isso acontecia, mas fica bem claro que a envolvência com os touros existia já e que nela estariam também incluídas de algum modo as crianças:
Planta enim fruticosa haec est, lauri folia habens, et illa quidem amarissima, ex cuius virgis, pueri in Hispania aclides, id est tela quaedam, acutis ferris ornata parant, quae in tauros eiaculantur.
De facto, esta é uma planta que tem muitos rebentos, apresentando folhas de louro que são, na verdade, muito amargas; dos seus ramos as crianças na Hispânia preparam gar- rochas, isto é, uns dardos, enfeitados com ferros afiados que lançam contra os touros.

Esta referência aos touros permite-nos trazer à colação um outro pequeno texto quinhentista que também aflora a temática das touradas e que foi publicado pela primeira vez uns anos antes ${ }^{13}$ por D. Jerónimo Osório:

12 Veja-se, por exemplo, a edição da Loeb Classical Library: Apuleıus, Metamorphoses. Edited and translated. by J. Arthur HANSON. Cambridge (MA), Harvard University Press, 1996. Veja-se também a versão portuguesa: APULEıo, O burro de ouro. Tradução e introdução de Delfim LEÃo. Lisboa, Livros Cotovia, 2007.

13 A editio princeps é de 1549, em Coimbra, embora a obra tenha sofrido algumas alterações para a edição
seguinte em 1552, agora em Florença. 
Hac etiam aetate, in Hispania praesertim, cum in ludis publicis undique spicula in tauros intorquentur, illi, qui magnam hominum stragem edunt, egregii tauri atque non uulgari pretio digni reputantur ${ }^{14}$.

No nosso tempo, sobretudo na Hispânia, quando, nos espetáculos públicos se atiram ferros contra os touros, aqueles que causam maior matança de homens são considerados touros notáveis e dignos de um preço não vulgar.

Sublinhe-se que também aqui a referência é muito sucinta, mas, que, apesar disso, consegue remeter para a realização pública destes espetáculos.

\section{DE FVNGIS - OS COGUMELOS}

$\mathrm{Na}$ enarratio seguinte $(86)^{15}$, o médico albicastrense fala dos cogumelos, considerando que se trata de um mau alimento "quos ego cum caeteris, tanquam noxios, ac pessimi et frigidi nutrimenti reiiciendos consulerem". Apesar desta opiniâo, para espanto do autor albicastrense, há um grupo considerável de pessoas que os considera como verdadeiros petiscos e, por essa razão, os contemporâneos de Amato descobriram uma maneira de produzir cogumelos em casa de forma intensiva, quase poderíamos dizer, e em condiçóes muito simples:

Caeterum tantus est hominum hodie luxus gulositasue, ut pro habendis quotidie fungis,
lapides quosdam excogitarint, quos in cellis vinariis, summa cura servant, et eos terra
cooperiunt, super quos, singulis octo vel decem diebus, fungi nascuntur

Ora, atualmente, é tão grande a intemperança e a gulodice dos homens que, para terem cogumelos, inventaram umas pedras que conservam com grande cuidado nas adegas e que recobrem bem com terra, sobre as quais, em cada oito ou dez dias, nascem cogumelos.

\footnotetext{
14 Utilizaremos a edição crítica incluída na nossa tese de doutoramento (João Manuel Nunes ToRRÃo, D. Jerónimo Osório e o tratado De gloria. I. Estudo. II. Edição Crítica. Coimbra, 1991 (tese de doutoramento policopiada) p. 155) em vez de outra mais recente pelas razões aduzidas em João Manuel Nunes TORRÃO, "D. Jerónimo Osório e o De gloria: um best-seller europeu de Quinhentos": em António ANDRADE, João TorRÃo, Jorge Costa e Júlio Costa (Coord.), Humanismo, diáspora e ciência. Estudos, catálogo e exposição. Porto, Universidade de Aveiro, Biblioteca Pública e Municipal do Porto, 2013, pp. 233-250. A edição crítica encontra-se disponível em: http://www2.dlc.ua.pt/classicos/Deglorialibriquinque.htm. Cf. Enarrationes, p. 419.
} 
Como se sabe, este gosto pelos cogumelos já vem da Antiguidade (tornou-se quase proverbial a morte de Cláudio através da ingestão de cogumelos venenosos ${ }^{16}$ ), e continuou até aos dias de hoje. Curiosamente, há técnicas atuais que estão muito próximas, mutatis mutandis, daquela que nos é apresentada por Amato. De facto, há atualmente cursos que ensinam a cultivar cogumelos em casa através da utilização, entre outras coisas, de caixas de cartão, troncos de madeira, fardos de palha (em vez das pedras referidas por Amato, que, eventualmente, também poderão ser utilizadas) e até garrafas plásticas de refrigerantes.

É, aliás, frequente encontrar anúncios a estes cursos de micologia e não são raros os que oferecem, como brinde, um kit de cultivo para a primeira produção. Neste caso, já não estamos a falar, necessariamente, de 'luxus gulositasue', mas de uma produção caseira para consumo doméstico com uma divulgação cada vez maior.

\section{DE ASTERE ATTICO- LÍRIO-CONVALE ${ }^{17}$ (?)}

A enarratio 121 do livro quarto ${ }^{18}$ apresenta-nos o aster Atticus sublinhando diversos nomes que lhe são atribuídos, bem como a confusão que alguns autores fizeram entre esta planta e outras que com ela têm algumas parecenças, embora sejam diferentes. Mais uma vez se recorre à autoridade de Galeno para apresentar algumas das suas propriedades.

Mais adiante, apoiando-se em outro autor, vai apresentar uma propriedade muito relevante:

et mirabilem habet proprietatem, scilicet ad reddendas steriles mulieres, fecundas illis quolibet mane coclear unum praedictae herbae, in pulverem redactae, cum brodio capi, vel vino generoso, per viginti dies, in potu propinando.

e tem uma caraterística admirável, a saber: a de tornar as mulheres estéreis, fecundas: dando-lhes a beber na bebida, pela manhã, uma colher da dita erva, reduzida a pó, para ser tomada com caldo ou com vinho generoso durante vinte dias.

16 Suetonius, Diuus Claudius. Edited by Donna W. Hurley. Cambridge, Cambridge University Press, 2001, 44.

17 Embora este não seja o termo mais adequado, estamos a utilizar aqui, na ausência de melhor hipótese, a tradução fornecida em: F. R. dos Santos SARAIVA, Novíssimo Dicionário LATINO-PORTUGUÊS. Etimológico, prosódico, histórico, geográfico, mitológico, biográfico, etc.. Rio de Janeiro-Belo Horizonte, Livraria Garnier, ${ }^{10} 1993$. De facto, de acordo com o nosso consultor para os assuntos de botânica, Jorge PaIva, não é conhecido o nome português que se atribui a esta planta.

18 Cf. Enarrationes pp. 433-434. 
Mas, se, até aqui, estava a citar outros autores, não deixa de dar a sua opinião que, aparentemente, estará baseada no conhecimento 'de experiência feito':

Quibus nos addimus, modo mulieres steriles fiant et non concipiant, quia ob lubricitatem humorum, semen genitale non retinent. Est enim herba haec constrictoria, et ea de causa, eius siccae herbae pulvis, iis qui ex alto cadunt, securissimo iuvamento conceditur, modo in decocto eiusdem herbae, vel aqua stillaticia detur, non minus quoque contra enterocelas valet, et muliebres menses constringit, imo ita mulierum genitalia constringit huius herbae decoctum, aut stillaticia aqua, ut corruptas aeque ac virgines reddat, modo super decocto, ad aliquot insedeant dies, non minus quoque pendentes mamillas, rotundas, ac duras, contractasue reddit.

Às quais nós acrescentamos agora as mulheres que se tornam estéreis e não concebem porque não retêm o sémen fecundo por causa da inconstância dos humores. Na verdade, esta erva é adstringente e, por esse motivo, o pó desta erva concede uma ajuda importantíssima àqueles que caem de grande altura, quer seja dada em decocto desta erva ou em água destilada; não tem menos valor também contra as enteroceles e restringe as menstruaçôes das mulheres. E o decocto desta erva ou a água destilada comprime de tal maneira os genitais das mulheres que torna as corruptas iguais às virgens desde que se sentem em cima do decocto por alguns dias: além disso, torna também as maminhas descaídas redondas e duras ou firmes.

Repare-se no final do texto de Amato. Sem fazer qualquer menção moral ou de qualquer outra espécie, apresenta uma propriedade caraterística desta planta já que serviria, por assim dizer, para 'recuperar' a virgindade.

Este texto, embora em contexto diferente, pode ser aproximado de uma reportagem que deu há tempos na televisão ${ }^{19}$ sobre o que aconteceu em França na altura em que as antigas colónias francesas do norte de África se tornaram independentes com o consequente regresso às terras de origem de muitas raparigas que se encontravam a estudar em França. Dizia a reportagem que houve uma procura inusitada de médicos que faziam a recuperação do hímen já que estas raparigas tinham assumido em França determinado tipo de comportamento cujos resultados físicos seriam muito mal recebidos nas sociedades bastante mais fechadas para onde iriam agora viver.

Poderíamos dizer que, se estas raparigas conhecessem este texto de Amato e tivessem acesso a esta planta e, já agora, se a planta tivesse, realmente, as propriedades que o médico albicastrense

19 Agradeço esta informação à Doutora Joana Catarina Mestre da Costa. 
lhe atribui, resolveriam em alguns dias o problema que as afligia e por um preço muito mais reduzido do que aquele que tiveram de pagar pela intervenção cirúrgica a que se tiveram de submeter.

\section{EM JEITO DE REMATE}

Estes exemplos, que se poderiam facilmente multiplicar, mostram-nos que Amato Lusitano se incorporava na cultura da sua época e no ambiente em que exercia a sua atividade, procurando em autores da Antiguidade a confirmação do seu saber que era, em simultâneo, um saber livreiro, no bom sentido do termo, misturado com um 'saber de experiência feito'.

Numa situação particular, ao falar sobre a cicuta, ao contrário do que lhe era habitual, o 'saber de experiência feito' não vai servir para contradizer as teorias da Antiguidade, mas deixa no ar a ambiguidade da questão.

Importa ainda sublinhar as aproximaçôes que podem ser feitas com a atualidade quer através de algumas situações com algum paralelismo, quer de outras onde a visão poderá ser quase antagónica.

\section{BIBLIOGRAFIA}

Amato Lusitano, IN DIOSCORIDIS / ANAZARBEI DE MEDICA / MATERIA LIBROS QVINQVE / ENARRATIONES ERVDITISSIMAE / DOCTORIS AMATI LVSITANI MEDICI / AC PHILOSOPHI CELEBERRIMI, / quibus non solum Officinarum Seplasia- / riis, sed bonarum etiam literarum stu- / diosis utilitas adfertur, quum pas- / sim simplicia Graece, Latine, / Italice, Hispanice, Germa- / nice, \& Gallice pro-/ponantur. / Cum Priuilegio Illustrissi. Senatus Veneti ad decennium. /VENETIIS / MDLIII. Apuleio, O burro de ouro. Tradução e introdução de Delfim LeÂo. Lisboa, Livros Cotovia, 2007.

Apuleius, Metamorphoses. Edited and translated. by J. Arthur Hanson. Cambridge (MA), Harvard University Press, 1996.

Galeno, DE TEMPERAMENTIS LIBRI III. / de inaeqvali intemperie liber I. Thoma Linacro Anglo Interprete. / Cum isagoge in eosdem libros et scholijs marginalibus / longe doctissimis, per Iacobum Syluium. / PARISIIS, / Ex officina Christiani wecheli, sub scuto Basiliensi, / in vico Iacobaeo: \& sub Pegaso, in vico / Bellouacensi. M. D. XLV.

Saraiva, F. R. dos Santos, Novíssimo Dicionário LATINO-PORTUGUÊS. Estimológico, prosódico, histórico, geográfico, mitológico, biográfico, etc.. Rio de Janeiro-Belo Horizonte, Livraria Garnier, ${ }^{10} 1993$.

Suetonius, Diuus Claudius. Edited by Donna W. Hurley. Cambridge, Cambridge University Press, 2001. 
Torrão, João Manuel Nunes, D. Jerónimo Osório e o tratado De gloria. I. Estudo. II. Edição Crítica. Coimbra, 1991 (tese de doutoramento policopiada)

Torrão, João Manuel Nunes, “D. Jerónimo Osório e o De gloria: um best-seller europeu de Quinhentos”, in António Andrade, João Torráo, Jorge Costa e Júlio Costa (Coord.), Humanismo, diáspora e ciência. Estudos, catálogo e exposição. Porto, Universidade de Aveiro, Biblioteca Pública e Municipal do Porto, 2013, pp. 233-250.

\section{SÍTIOS DA WEB}

http://cidadaniatransparencia.blogspot.pt/2013/11/remedio-feito-de-fezes-humanas-pode.html.

http://www.ecycle.com.br/component/content/article/38-no-mundo/1764-tratamento-coreano-utiliza-vinhomedicinal-feito-com-fezes-humanas.html

http://www.paulopes.com.br/2010/11/padre-continua-defender-que-pocao-base.html. 
A partir dos alvores do século XVI, a matéria médica torna-se indiscutivelmente um tema de primeira grandeza entre os membros da República das Letras, objecto de estudo e de controvérsia entre os mais notáveis humanistas europeus, em particular entre os cultores da arte médica. Entre os autores em destaque neste volume encontram-se, à cabeça, os nomes de Amato Lusitano, Garcia de Orta e Nicolás Monardes, famosos pelos contributos valiosos que deram para o conhecimento do mundo natural. 0 volume encontra-se dividido em duas partes: a primeira, subordinada ao título "Humanismo e Ciência", alberga os estudos que versam sobre todos os autores estudados, à excepção de Amato Lusitano; a segunda está reservada a um conjunto de trabalhos dedicados exclusivamente ao médico albicastrense, cuja autoria se fica a dever, em boa parte, aos membros da equipa do projecto de I\&D "Dioscórides e o Humanismo Português: os Comentários de Amato Lusitano", tomando, por isso, 0 seu próprio título. Nesta segunda parte, oferece-se, desde já, aos leitores uma amostra significativa do trabalho desenvolvido no âmbito do projecto e que culminará, assim se espera, na edição e tradução integral para língua portuguesa das quatro obras previstas de Dioscórides, Amato Lusitano e Pietro Andrea Mattioli. 
